\title{
NEURITE REGENERATION BY APLYSIA NEURONS IN DISSOCIATED CELL CULTURE: MODULATION BY APLYSIA HEMOLYMPH AND THE PRESENCE OF THE INITIAL AXONAL SEGMENT ${ }^{1}$
}

\author{
SAMUEL SCHACHER ${ }^{2}$ AND ERIC PROSHANSKY \\ Departments of Anatomy and Psychiatry, Center for Neurobiology and Behavior, College of Physicians and Surgeons, Columbia \\ University, and The New York State Psychiatric Institute, New York, New York 10032
}

Received March 17, 1983; Revised May 31, 1983; Accepted June 6, 1983

\begin{abstract}
Neurons from the abdominal ganglion of the mollusc Aplysia californica regenerate neurite processes in dissociated cell culture. Both the nature of neurite outgrowth and the morphology of the cells are influenced by the presence of adult Aplysia hemolymph in the growth medium and the presence of a portion of a cell's original axonal process. Aplysia hemolymph enhances cell survival, the initiation of neurite outgrowth from multiple sites on the cell body surface, the linear growth of the processes, and the amount of branching by those processes. Ilemolymph also decreases the diameter of the outgrowing neurite fascicles and the diameter of the individual neurites within the fascicles. The presence of a cell's original axon reduces the time required for the initiation of neurite outgrowth and restricts the formation of multipolar processes. In addition, the presence of an initial axonal segment is essential for neurite regeneration from large adult neurons.
\end{abstract}

Before neurons can form synaptic connections with distant targets, they must initiate neurite outgrowth and project these neuritic processes toward the correct target zone. Thus, the pattern of synaptic connections and the morphological properties of a neuron are influenced by factors which affect neurite outgrowth during early development.

Dissociated cell culture techniques have been utilized extensively for studying neurite outgrowth and development of vertebrate neurons. Using this simple system approach, investigators have succeeded in identifying a variety of chemical factors which can influence neuron survival, initiation and direction of neurite outgrowth, neurite extension, and aspects of biochemical differen-

\footnotetext{
${ }^{1}$ This work was supported by National Institutes of Health Grant NS19216 and National Science Foundation Grant 7923602 to S. S., Sloan Foundation Postdoctoral Fellowship to E. P., and National Institutes of Health Grant GM32099 which supports the mariculture facility at the Marine Biological Laboratory, Woods Hole, MA. We wish to thank R. Woolley, L. Shanet, and K. Hilten for technical assistance and preparing figures. We also would like to thank T. Capo and S. Perritt for raising the animals at the Marine Biological Laboratory. We also thank E. Kandel, R. Ambron, V. Castellucci, and J. Camardo for their comments on earlier drafts of this manuscript.

${ }^{2}$ To whom correspondence should be sent, at Center for Neurobiology and Behavior, Columbia University, and New York State Psychiatric Institute, 722 West 168th Street, New York, NY 10032.
}

tiation or synapse formation (Levi-Montalcini, 1976; Campenot, 1977; Letourneau, 1978; Patterson, 1978; Varon and Bunge, 1978; Jessel et al., 1979; Nishi and Berg, 1981). In some cases, it has been shown that these factors can differ from one another in terms of tissue specificity, mechanisms of action, or the number of effects they can exert on a given cell type.

Recently, dissociated cell culture techniques have been extended to studying identified central neurons of invertebrates such as the leech, Helisoma, and Aplysia (Kaczmarek et al., 1979; Ready and Nicholls, 1979; Dagan and Levitan, 1981; Wong et al., 1981). Because many of these invertebrate neurons are large and their properties have been well characterized in vivo (Kandel, 1976; Kaneko et al., 1978; Muller et al., 1981), a variety of cell biological methods can be applied to examine regeneration and the specificity of synapse formation under experimentally controlled conditions (Fuchs et al., 1981, 1982; Wong et al., 1981, 1983; Camardo et al., 1983). With regard to neurite regeneration, Kater and his colleagues (Barker et al., 1982) have identified two separate factors released by the adult central nervous system of Helisoma that can affect either neurite extension or certain metabolic activities of Helisoma cells.

In Aplysia, the neuroendocrine bag cells of the abdominal ganglion (Kaczmarek et al., 1979) and unidentified buccal ganglion neurons (Dagan and Levitan, 1981) have 
been shown to extend neuritic processes in dissociated cell culture. When plated as isolated cell bodies in medium supplemented with fetal calf serum, these cells extend multiple processes, show electrophysiological properties that appear normal, and form electrotonic connections.

We have extended these earlier studies in Aplysia to determine the conditions which influence neurite regeneration and the morphology of identified neurons in the abdominal ganglion. We have found two conditions that have profound effects on neurite growth. First, medium supplemented with adult Aplysia hemolymph affects cell survival, initiation of neurite outgrowth, the rate of neurite extension, and the morphology of the regenerated processes. Second, we find that the presence of a segment of the original axon significantly alters the way a given cell regenerates its neuritic processes by restricting outgrowth from additional sites on the cell body.

\section{Materials and Methods}

Animals and cell preparation. Juvenile (1 to $2 \mathrm{gm}$; stage 12 ) or adult (50 to $100 \mathrm{gm}$ ) Aplysia californica, grown from fertilized eggs (Kriegstein et al., 1974; Kriegstein, 1977) at the Marine Biological Laboratory at Woods Hole, MA, were anesthetized with sterile isotonic $\mathrm{MgCl}_{2}$ for 10 to $20 \mathrm{~min}$. The animals were pinned out in a dish coated with Sylgard (Dow Corning Corp., Midland, MI), and the abdominal ganglia were removed under sterile conditions in a laminar flow hood. The ganglia were treated with $1 \%$ protease (Sigma type IX) in isotonic $\mathrm{L} 15$ medium (see below) for 2 to $2.5 \mathrm{hr}$ at $34^{\circ} \mathrm{C}$, washed several times, and transferred to another sterile Sylgardcoated dish containing isotonic L15 medium with $1 \%$ fetal calf serum (FCS). The presence of FCS (Flow Laboratories, Inc., McClean, VA) prevented isolated cells from sticking to the surface of the dissociating dish or the glass capillary tubes used for cell transfer. The ganglia were pinned with the tips of glass microelectrodes and desheathed. The left upper quadrant cells (L2 to L6; LUQ cell), identified on the basis of position, size, pigmentation, and axon distribution (Koester and Kandel, 1977), were hand dissected from the ganglia with finetipped microelectrodes in one of two ways. Each LUQ cell in the ganglion was removed with its initial axonal process $(100$ to $500 \mu \mathrm{m})$ by gently touching the soma with the electrode and pulling it slowly away from the ganglion in a direction that is opposite to the nerve in which that cell's axon projects to the periphery. The fine electrode forms a seal on a patch of soma membrane that is strong enough to allow the cell with its trailing axonal process to be removed with no apparent damage. Alternatively, the LUQ cells were removed without their axons by impaling each axon near the cell body after partial removal from the ganglion using the method described above. All LUQ cells from a single ganglion (juvenile or adult) were transferred by capillary micropipettes to a culture dish.

Random populations of dissociated abdominal ganglion cells from juvenile animals were obtained by impaling a desheathed ganglion and underlying Sylgard simultaneously with a microelectrode, bending the electrode by downward pressure, and quickly releasing the
TABLE I

Effects of hemolymph on neurite initiation

Hemolymph enhances neurite initiation measured as percentage of attached cells that sprouted one process longer than $20 \mu \mathrm{m}$. Each value is an average of the mean from 10 dishes except for day 4 measurements of L15 and L15-50\% HEMO ( $N=5$ each). For L15-50\% hemolymph cultures, the L15 medium in five dishes was replaced on the 2nd day with $50 \%$ hemolymph. For L15 cultures, on day 4, cells with degenerating processes were included in the sample and were scored as having sprouted neurites. For each day, the sprouting efficiency in the hemolymph cultures is significantly greater than that of the non-hemolymph cultures.

\begin{tabular}{lccccccc}
\hline & \multicolumn{5}{c}{ Sprouting Efficiency (\%) } \\
\cline { 2 - 8 } & $5 \%$ FCS & $10 \%$ HEMO & $25 \%$ HEMO & $50 \%$ HEMO & L15 & $\begin{array}{c}\text { L15-50\% } \\
\text { HEMO }\end{array}$ \\
\hline Day 1 & 14 & 51 & 77 & 79 & 30 & \\
Day 4 & 41 & 86 & 96 & 98 & 47 & 85 \\
\hline
\end{tabular}
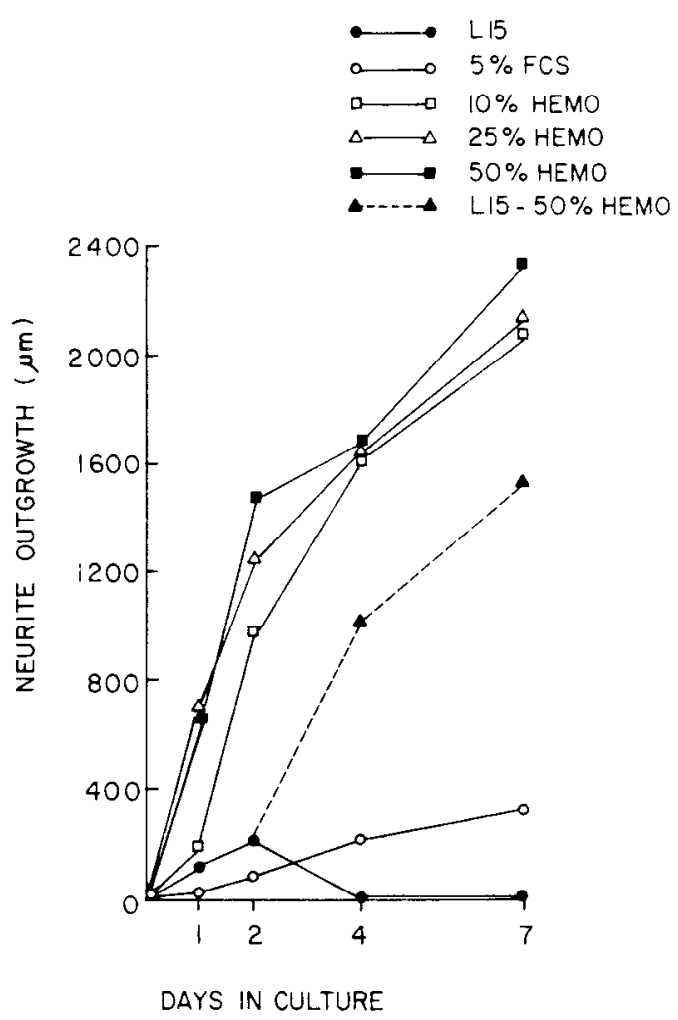

Figure 1. Neurite outgrowth by random populations of abdominal ganglion neurons from juvenile animals grown in media with or without hemolymph. Each point is the average of the means from 10 culture dishes except for the day 4 and day 7 points for L15 (solid circles) and L15-50\% HEMO (solid triangles, dashed line) which represent the average of five culture dishes each. In each dish, 10 to 25 growing cells were measured (sum of three longest processes) except for the day 1 point for $5 \%$ FCS. These culture dishes typically had fewer than 10 cells growing at this time. On day 2, the isotonic L15 medium in five dishes was replaced by $50 \%$ hemolymph. Another five dishes were left unchanged. Since cells in all of the isotonic L15 cultures showed signs of degeneration on day 4 (see Fig. $3 A$ ), a score of 0 growth was given to these cultures. The growth in the hemolymph media was significantly greater ( $p<0.01$; two-tailed $t$ test) than in non-hemolymph cultures at all time points. 
pressure. The "flicking" motion of the electrode severed the cell bodies from their axonal processes. On average, each ganglion dissociated in this manner provided enough cells for plating four culture dishes ( 40 cells/dish) containing different growth media.

Tissue culture dishes and growth media. Tissue culture dishes (Falcon, no. 1006) were pretreated with $0.1 \%$ polyL-lysine (Sigma, $M_{\mathrm{r}}=400,000$ ) in $0.1 \mathrm{M}$ sodium borate, $\mathrm{pH} 8.2$ (Ready and Nicholls, 1979) for 24 to $48 \mathrm{hr}$, then rinsed extensively with water and isotonic L15 medium just prior to use. Isotonic L15 medium contained L15 (Flow Laboratories) plus appropriate salts so that the final salt concentrations were the following: $400 \mathrm{~mm}$ $\mathrm{NaCl} ; 11 \mathrm{~mm} \mathrm{CaCl} 2 ; 10 \mathrm{~mm} \mathrm{KCl} ; 27 \mathrm{mM} \mathrm{MgSO}_{4} ; 27 \mathrm{mM}$ $\mathrm{MgCl}_{2} ; 2 \mathrm{mM} \mathrm{NaHCO}$. In addition to the salts, $6 \mathrm{mg} / \mathrm{ml}$ of dextrose and $0.1 \mathrm{mg} / \mathrm{ml}$ of glutamine (Flow Laboratories) were added to the L15.
The cells were grown in the following media: (1) isotonic L15; (2) isotonic L15 plus 5\% FCS; (3) isotonic L15 plus 10, 25, or $50 \%$ sterile filtered Aplysia hemolymph. The hemolymph was withdrawn by syringe from the body cavity of adult animals (100 to $200 \mathrm{gm}$ ) obtained from Pacific Biomarine (Venice, CA). The media, which contained no antibiotics, were changed every 2 days with the same original stock used at initial plating. Cultures were maintained in the dark at room temperature.

Measurement of neurite outgrowth and morphology. Two parameters of neurite outgrowth (initiation and elongation) were measured on populations of unidentified cells dissociated from juvenile ganglia with cell body diameters between 40 and $80 \mu \mathrm{m}$. Neurite initiation was calculated as the percentage of attached cells that sprouted one process greater than $20 \mu \mathrm{m}$ (sprouting efficiency). Neurite elongation for a cell on a given day
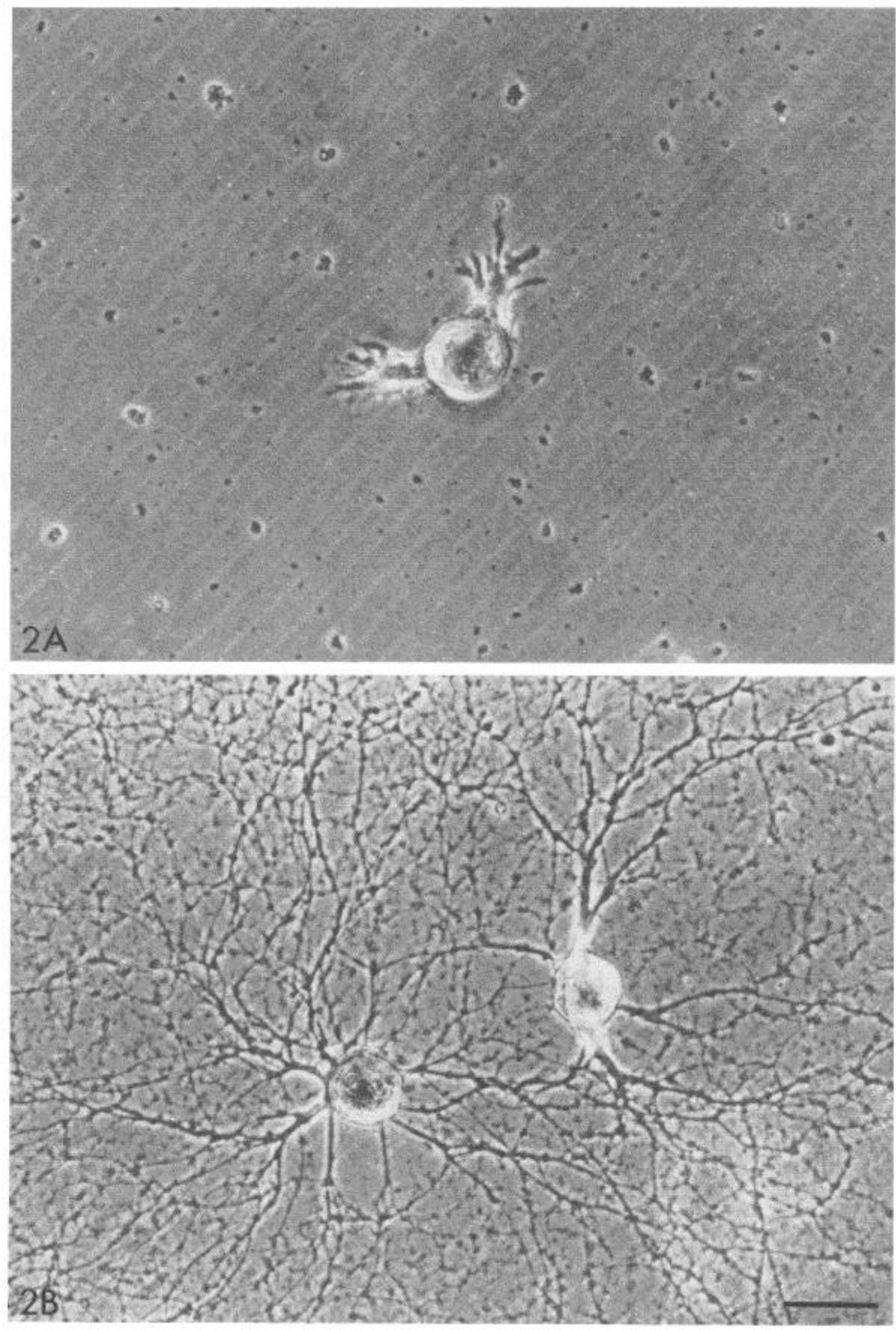

Figure 2. Neurite outgrowth from juvenile cells after 2 days in culture. $A$, Cells grown in $5 \%$ FCS. Note the thickness of the short processes emerging from the cell body. $B$, Cells grown in $50 \%$ hemolymph. The cells have grown numerous and highly branched processes from their cell bodies. The bar equals $50 \mu \mathrm{m}$. 
was determined by summing the linear extent of the three longest processes from the tip of each process to the soma surface. All measurements were made on living cells with a calibrated ocular micrometer viewed under an inverted Leitz microscope. Measurements of neurite extension were made on all cells in each culture dish except those that had formed interconnected neuritic networks.

Five parameters of neurite growth from all LUQ cells plated without axons were measured by light and electron microscopy. After 4 days in culture, measurements of the number and width of processes emerging from the cell body and the linear extent of the three longest processes were made by direct observation on the inverted light microscope at magnifications of $\times 100$ or $\times 400$. To calculate the extent of branching (branching ratio), a circle with a radius of $300 \mu \mathrm{m}$ was drawn around photographs of each cell, and the number of peripheral proc- esses intersected by the circle was divided by the number of processes emerging from the cell body. Measurements of process width were also made on these photographs and were identical to those obtained by direct observation.

The cells were then prepared for electron microscopy by slow perfusion of $2 \%$ glutaraldehyde in $0.1 \mathrm{M}$ phosphate buffer with $20 \%$ sucrose ( $\mathrm{pH} 7.4$ ) for $30 \mathrm{~min}$, rinsed in buffer, postfixed with $1 \% \mathrm{OsO}_{4}$ in phosphate buffer, dehydrated, and embedded in Medcast (Ted Pella, Inc., Tustin, CA). The embedded cells were stripped off the plastic culture dishes, glued on blank Medcast blocks, thin sectioned, stained with uranyl acetate and lead citrate, and examined with a Philips 301 electron microscope. For each cell, 5 to 10 photographs of neurite fascicles of comparable widths were used to calculate the average diameter of the regenerate neurites.

Axotomy of identified cells in culture. LUQ cells from
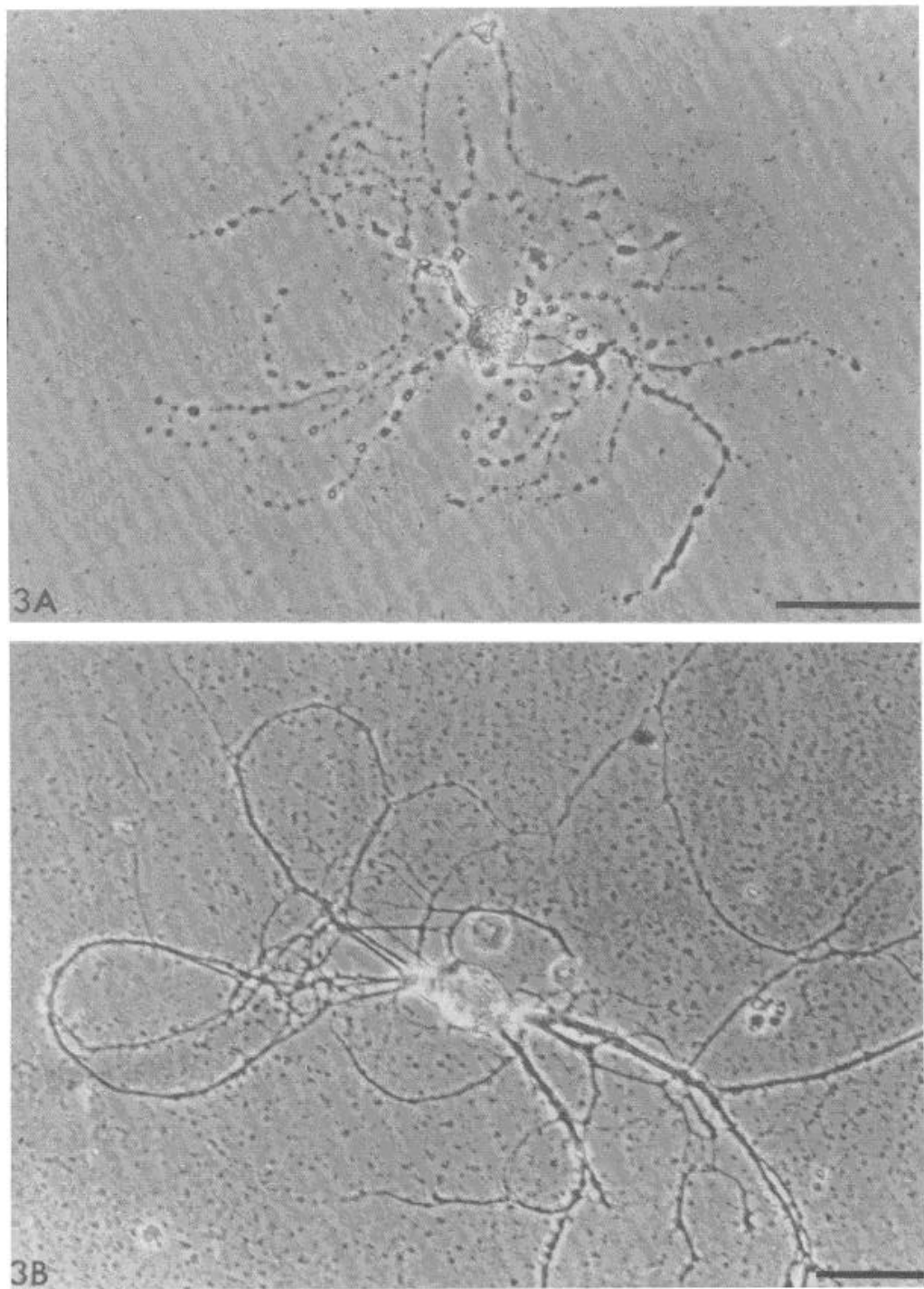

Figure 3. Cell survival and neurite outgrowth by juvenile cells is enhanced by hemolymph. $A$, Cell grown in isotonic L15 after 4 days. Note the extensive fragmentation of the processes that is typical of cell degeneration. $B$, Cell grown in $50 \%$ hemolymph for 2 days after growth in isotonic $\mathrm{L} 15$ for 2 days. The bars equal $100 \mu \mathrm{m}$. 
juvenile ganglia, with and without axonal processes, were plated together in culture dishes. After 2 days, some of the cells plated with axons in each dish had their primary axons and the regenerated processes removed by cutting the axon near the cell body with a fine-tipped microelectrode and lifting the detached axon from the substrate. Of the 12 cells treated this way, 7 cells survived and regenerated processes. The other cells showed signs of degeneration $1 \mathrm{hr}$ after axotomy.

\section{Results}

Initiation of neurite outgrowth is accelerated by hemolymph. The initiation of neurite outgrowth for random populations of abdominal ganglion cells is markedly enhanced by the presence of hemolymph (Table I). When the cultures achieve their maximal level of sprouting on day 4, nearly all of the cells ( 86 to $98 \%$ ) in the hemolymph cultures have sprouted processes compared to about $45 \%$ observed in the $5 \% \mathrm{FCS}$ or L15 cultures.

Hemolymph appears to influence neurite initiation directly and not by affecting the initial attachment of the cells to the substrate. Nearly all of the cells (90 to $95 \%)$ plated in the different media are attached to the substrate after 2 days in culture. In addition, when hemolymph is added to cells initially grown in L15 (L15$50 \%$ HEMO), the cultures show a sprouting efficiency comparable to that seen for cultures maintained in hemolymph for the entire period.

Neurite elongation is enhanced by hemolymph. Once initiated, the further outgrowth of neurites is also enhanced by the presence of hemolymph (Figs. 1 to 3 ). The effect of hemolymph on growth is most dramatic during the first 2 days (Fig. 1). Since measurements are made on all sprouting cells, some of this increase can be accounted for by hemolymph's differential effect on neurite initiation, which would stagger the length of time different cells in a given culture are elongating their processes. However, after the steady-state level for neurite initiation is achieved at 4 days in culture, the hemolymph cultures have grown to a level that is 7.5 -fold greater than that seen in $5 \%$ FCS cultures.

In addition to enhancing the linear growth of neurites, hemolymph also alters aspects of neurite growth. Growth by cells in FCS is characterized by short and relatively few (two to four) processes emerging from the cell body (Fig. $2 A$ ). These processes are 10 -fold wider than processes emerging from cells grown in $50 \%$ hemolymph (Fig. $2 B$ and below).

The presence of hemolymph also affects cell suryival. Although cells grown in isotonic L15 attach to the substrate and sprout processes which grow ovér a 2-day period, on day $4,90 \%$ of the sprouted cells show initial signs of degeneration (solid circles in Fig. 1 and Fig. $3 A$ ). The degeneration can be reduced to $10 \%$ of the growing cells and neurite outgrowth can be enhanced when the isotonic L15 medium is replaced after 2 days by $50 \%$ hemolymph (dashed line in Fig. 1 and Fig. $3 B$ ).

Neurite outgrowth and morphology of LUQ cells is modified by hemolymph. The data described above indicate that the presence of $10 \%$ to $50 \%$ hemolymph in the medium enhances the survival and extent of neurite outgrowth for small (40 to $80 \mu \mathrm{m}$ ) neurons to equivalent levels. We extended these studies to examine the regenerative capacity of larger juvenile cells, L2 to L6 (LUQ cells), with cell body diameters between 100 and $150 \mu \mathrm{m}$. We find that the LUQ cells are affected by hemolymph to a greater extent than smaller cells derived from the same ganglia. In the absence of hemolymph (isotonic L15 or $5 \%$ FCS), only $10 \%$ of the LUQ cells that attach to the substrate sprout processes after 4 days compared to about $45 \%$ for smaller cells (see Table I). Both the extent and the morphology of neuritic growth are comparable to those seen for smaller cells grown under identical conditions (e.g., Fig. $2 A$ ). In the presence of $10 \%$ to $50 \%$ hemolymph, 80 to $90 \%$ of the LUQ cells plated without axons sprout processes between 6 and $24 \mathrm{hr}$ after plating. In addition, all five LUQ cells derived from the same ganglion and plated in a single culture dish containing either $10 \%, 25 \%$, or $50 \%$ hemolymph show comparable patterns of growth after 4 days. However, the pattern of neurite growth is affected by changing the level of hemolymph in the medium (Table II, Figs. 4 and 5).

When LUQ cells from juvenile ganglia are grown in the various hemolymph media, four differences in neurite regeneration and morphology are observed at the light microscope level (Table II and Fig. 4). Growth in 50\% hemolymph is characterized by many fine processes emerging from the cell body which branch extensively as the processes move away from the cell body (Fig. $4 \mathrm{C}$ ). In contrast, cells grown in $10 \%$ hemolymph sprout fewer but wider processes from the cell body which give rise to significantly fewer branches (Fig. $4 A$ ). Cells grown in $25 \%$ hemolymph show neurite growth with intermediate properties (Fig. $4 B$ ). In addition, we find that, unlike the smaller cells where no differences in neurite extension are seen in 10 to $50 \%$ of hemolymph (e.g., Fig. 1), the linear extent of neurite outgrowth for LUQ cells in 25 or $50 \%$ cultures are both significantly greater $(60$ and $70 \%$, respectively) than the growth measured for $10 \%$ cultures (Fig. 4).

At the electron microscope level, another difference in

\section{TABLE II}

Effects of hemolymph on neurite outgrowth from LUQ cells

Hemolymph alters the pattern of neurite outgrowth from juvenile LUQ cells plated as isolated somata and maintained in culture for 4 days. Each measurement is the average of the means \pm SD from 10 cells, except for measurements of neurite diameter $(N-5$ each). Process thickness is measured at the point of emergence from the cell body. The branching ratio is the number of processes $300 \mu \mathrm{m}$ from the center of the cell soma divided by the number of processes emerging from the cell body. The diameter of individual neurites was measured from electron micrographs of the neurite fascicles. A one-way analysis of variance showed an overall significant difference between groups for each parameter $(p<0.01)$.

\begin{tabular}{lcccc}
\hline & \multicolumn{3}{c}{$\%$ Hemolymph in Medium } & \\
\cline { 2 - 4 } & 10 & 25 & 50 & \\
\hline $\begin{array}{c}\text { No. of Processes } \\
\text { Emerging from }\end{array}$ & $8.8 \pm 1.3$ & $11.0 \pm 2.1$ & $21.2 \pm 2.1$ & $(p<0.01)$ \\
$\quad$ Cell Body & & & & \\
$\begin{array}{c}\text { Process Thick- } \\
\text { ness ( } \mu \mathrm{m})\end{array}$ & $9.9 \pm 0.4$ & $6.5 \pm 1.6$ & $3.3 \pm 1.4$ & $(p<0.01)$ \\
Branching Ratio & $1.7 \pm 0.3$ & $2.3 \pm 0.3$ & $3.7 \pm 0.4$ & $(p<0.01)$ \\
$\begin{array}{c}\text { Neurite Diameter } \\
(\mu \mathrm{m})\end{array}$ & $2.8 \pm 1.3$ & $1.1 \pm 0.1$ & $0.6 \pm 0.2$ & $(p<0.01)$ \\
& & & &
\end{tabular}



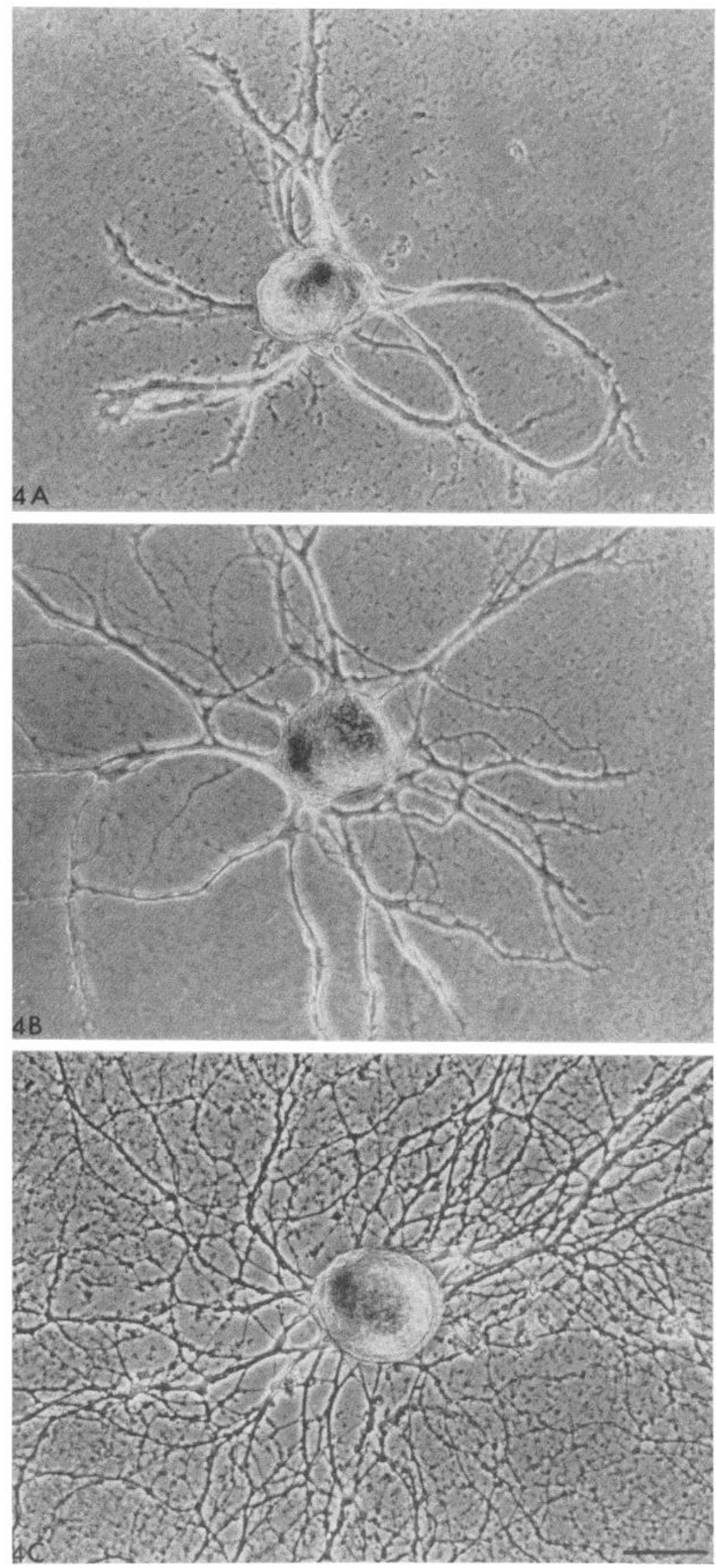

Figure 4. LUQ cells from juvenile ganglia grown for 4 days in media containing different levels of hemolymph. A, LUQ cell grown in $10 \%$ hemolymph. These cells $(N=10)$ have grown $1380 \mu \mathrm{m}$ of processes. $B$, LUQ cell grown in $25 \%$ hemolymph. These cells $(N=10)$ have grown 2190 $\mu \mathrm{m}$ of processes. Neurite outgrowth is significantly greater than that seen for cells grown in $10 \%$ hemolymph $(p<0.01)$. $C$, LUQ cell grown in $50 \%$ hemolymph. These cells $(N=10)$ have grown $2360 \mu \mathrm{m}$ which is significantly greater $(p<0.01)$ than that seen in $10 \%$ hemolymph but not significantly greater than that seen in $25 \%$ hemolymph. The bar equals $100 \mu \mathrm{m}$. 

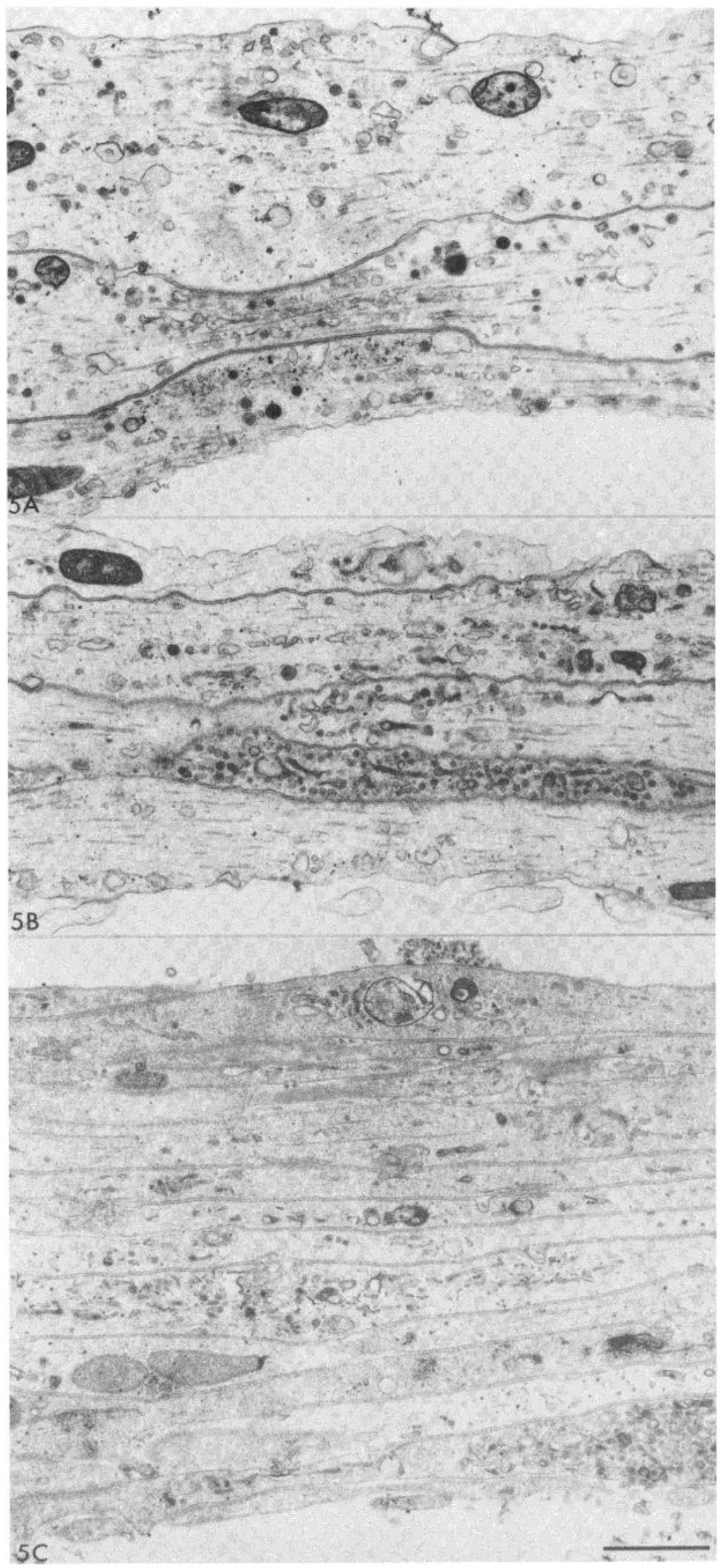

Figure 5. Neurite outgrowth from LUQ cell is characterized by fasciculation. The diameter of the individual neurites decreases as hemolymph levels in the growth medium increase. Note that the complement of axonal organelles (vesicles, mitochondria, endoplasmic reticulum, lysosomal bodies, and microtubules) present in the neurites is not altered by the growth medium. The bar equals $1 \mu \mathrm{m}$. $A, 10 \%$ hemolymph; $B, 25 \%$ hemolymph; $C$, $50 \%$ hemolymph. 
neurite morphology can be observed (Table II and Fig. $5)$. The individual processes emerging from the cell body that are seen at the light microscope level are composed of fascicles of finer diameter neurites (Fig. 5). Increasing the hemolymph level in the medium decreases the diameter of these finer neurites (Table II). However, no differences are observed in the types of organelles present in the neurites (Fig. 5).

Multipolar outgrowth is inhibited by the presence of the original axonal process. Our results thus far indicate that the LUQ cells, which are unipolar in vivo, regenerate multipolar processes when cultured as isolated cell bodies. We therefore examined how LUQ cells regenerate processes when each is plated as a cell body attached to a section of its original axon. Under these conditions, the time required for the initiation of neurite regenera- tion is reduced (Fig. 6A) and the number of processes emerging from the cell body is markedly decreased (Figs. $6 B$ and 7 ).

When plated with an axon, LUQ cells begin to regenerate neuritic processes after $1 \mathrm{hr}$ (Fig. $6 A$ ). The growth invariably occurs at the cut ends of the axons. By $24 \mathrm{hr}$, processes emerging from the axon stump have elongated at rates comparable to that observed for isolated cell bodies (Fig. 6B). However, unlike the regeneration seen for isolated cell bodies, the LUQ cells retain their unipolar configuration. With time in culture, additional processes subsequently emerge from proximal portions of the axon and the cell body so that, by day 4, the cells show four additional processes emerging from the cell body (open squares in Fig. 7). On the other hand, LUQ cells plated as isolated somata and growing in the same
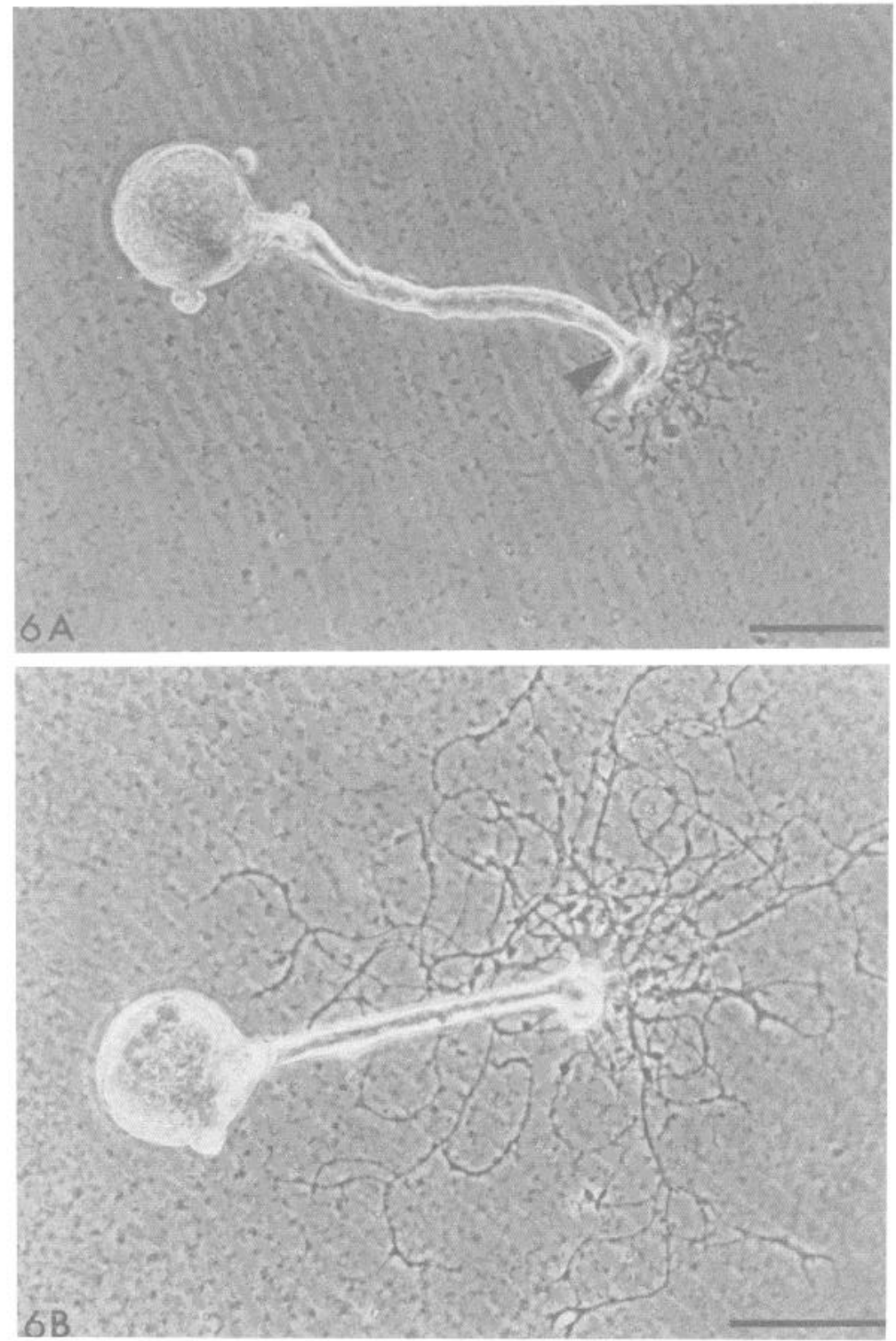

Figure 6. Neurite outgrowth by a juvenile LUQ cell plated with a segment of its original axon. $A$, Neurite outgrowth from the axon stump (arrowhead) after $1.5 \mathrm{hr}$ in culture. $B$, Neurite outgrowth from the axon stump $20 \mathrm{hr}$ after plating. Note that all growth occurs from the axon stump. The bars equal $125 \mu \mathrm{m}$. 


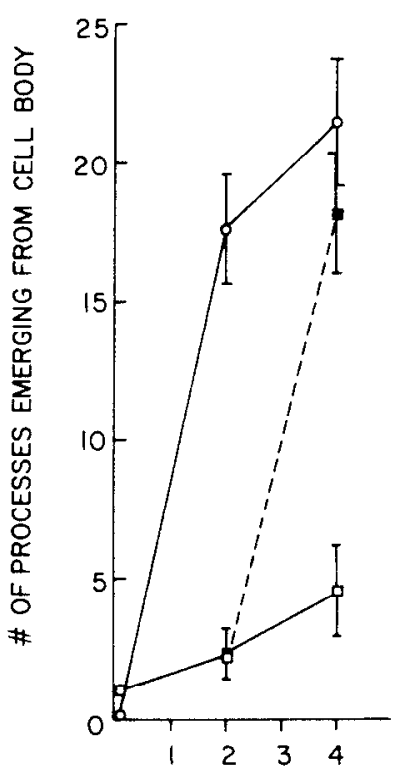

DAYS IN CULTURE

Figure 7. The extent of multipolar outgrowth for juvenile LUQ cells plated as isolated cell bodies or with axons. Each point is the average of 20 cells except for the 4 -day points for cells plated with axons (open squares; $N=8$ ) and cells plated with axons followed by axotomy on day 2 (solid squares; $N=$ 7). Multipolar growth for cell axons plated initially without (open circles) or after axotomy in culture is significantly greater $(p<0.01)$ than that seen for cells plated with axons.

culture dishes have grown 17 and 22 processes by day 2 and day 4, respectively (open circles in Fig. 7).

The formation of multipolar processes by LUQ cells appears to result from axotomy at sites near the cell body (axon hillock). When the axon is cut at the axon hillock after the cells have been in culture for 2 days, the number of processes formed by 4 days is comparable to that seen for cells plated initially as isolated cell bodies (dashed line in Fig. 7 and Fig. 8).

Large adult cells require initial process for neurite outgrowth. Isolated cell bodies of neurons from adult abdominal ganglia retain their normal electrophysiological properties (Dagan and I evitan, 1981). Under the culture conditions described here, however, large adult abdominal ganglion neurons with cell body diameters greater than $200 \mu \mathrm{m}$ will not initiate neurite outgrowth unless they are plated with a short segment of axon. The growth from the axon stump begins about $12 \mathrm{hr}$ after plating (compared to $1 \mathrm{hr}$ for their younger counterparts) but then proceeds rapidly. By 3 days, the cells have regenerated large and highly branched neuritic fields (Fig. 9).

\section{Discussion}

The results reported here suggest that neurite regeneration from Aplysia neurons is influenced by factor(s) present in hemolymph and the cell's original axon. Hemolymph enhances cell survival and the initiation and extension of outgrowth. In addition, the pattern and morphology of the regenerated processes, such as the formation of multiple processes, neurite diameter, and branching, are affected by the level of hemolymph in the growth medium. The presence of the axon also affects the pattern of regeneration. Under these conditions, the site of neurite outgrowth is restricted primarily to the axon stump and multipolar growth is reduced. The observations on regeneration from cells plated with and without axons are comparable to earlier reports for in vivo regeneration by identified neurons in leech (Nicholls et al., 1977) and Helisoma (Murphy and Kater, 1978, 1980; Hadley and Kater, 1983). In these preparations, injury to axons at distal sites restricted regeneration to peripheral axonal locations, whereas injuries placed at more proximal positions resulted in additional central regeneration from the soma.

The requirement of hemolymph for survival and its effects on neurite outgrowth may vary for different abdominal ganglion cells. For example, the neuroendocrine bag cells from adult abdominal ganglia can survive for several weeks in isotonic L15 medium (Kaczmarek et al., 1979). Our data show that low hemolymph levels reduce neurite extension from LUQ cells but have little effect on smaller cells. Since a variety of identified abdominal ganglion cells can now be placed in culture (Schacher et al., 1982; Camardo et al., 1983), culture conditions affecting survival, neurite outgrowth, and morphology can be determined for specific cell types.

Hemolymph may influence growth through a single molecule with properties similar to those of nerve growth factor (Levi-Montalcini, 1976) or through separate factors, soluble or substrate adhering (Letourneau, 1975; Collins, 1978, 1980; Adler et al., 1981; Nishi and Berg, 1981; Barker et al., 1982; Wong et al., 1983), which affect specific aspects of regeneration. From preliminary results, it appears that hemolymph may contain separate factors. For example, the cell survival "factor" is heat stable, whereas those that influence initiation, elongation, and morphology are not. In addition, factors affecting initiation and extension may be separated by their differential adherence to the substrate. Passing hemolymph over a series of polylysine-treated dishes does not significantly affect the growth-promoting influence that the hemolymph subsequently produces on unidentified cells. The hemolymph-treated dishes, however, may enhance neurite initiation (L. Shanet and S. Schacher, manuscript in preparation). Additional experiments along these lines will enable us to separate and characterize these hemolymph factors and determine their influences on identified Aplysia neurons.

Our observations concerning the role of the axon and axon hillock on regeneration from Aplysia neurons may reflect events that occur during in vivo development. Aplysia neurons, as well as most other invertebrate cells, typically sprout a single axon from the cell body (Schacher et al., 1979; Goodman and Pearson, 1982). The restriction placed on additional sites for axonal growth might be accomplished by the formation of a rigid cytoskeletal structure critical for the maintenance of neuronal shape (Bray and Gilbert, 1981; Lasek and Shelanski, 1981). In addition, the axon hillock of Aplysia neurons may be a critical site for neuronal branching. Differentiated Aplysia neurons, including the LUQ cells, typically show extensive neurite branching at the axon hillock (Winlow and Kandel, 1976). Indeed, the importance of this axon segment is best seen for neurite regeneration by adult Aplysia cells (e.g., Fig. 9). On the other hand, when a cell is axotomized at the axon hillock, 

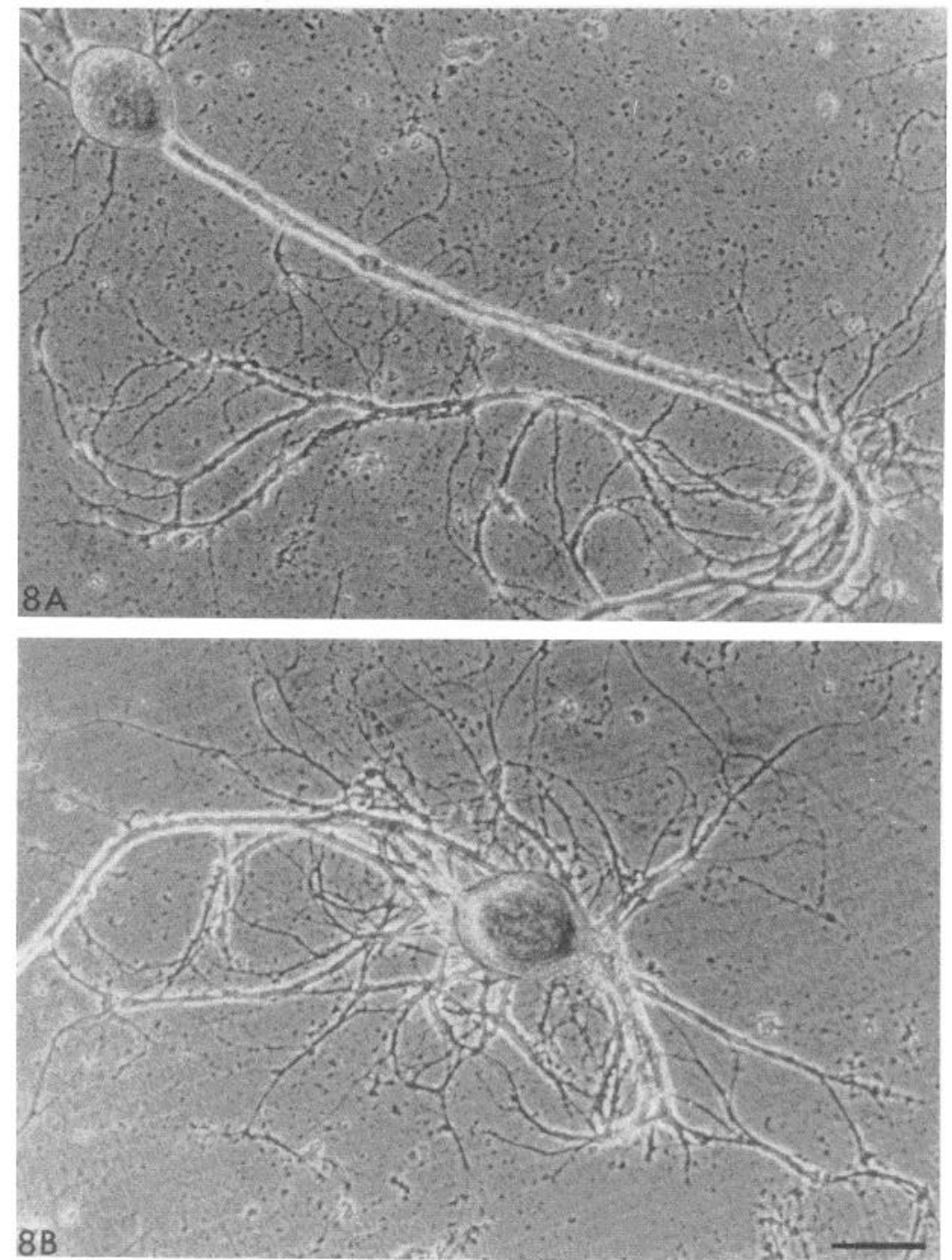

Figure 8. Multipolar growth following axotomy. A, LUQ cell plated with axon after 2 days in culture. Note that most of the growth is from the axon stump. Several additional processes can be seen emerging from the cell body and proximal portions of the axon. $B$, The identical cell 2 days after cutting the primary axon. Note the numerous processes now emerging from the cell body. The bar equals $100 \mu \mathrm{m}$.

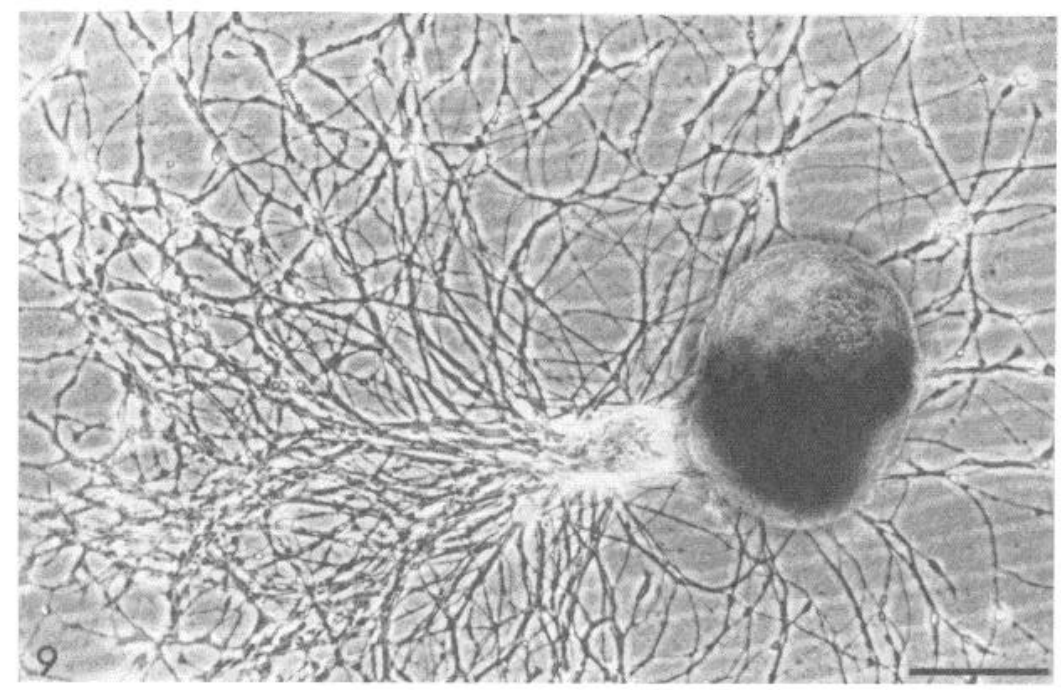

Figure 9. Adult LUQ cell in culture for 3 days. Note that neurite outgrowth emerges from the axon stump and from proximal axonal sites very close to the cell body. The processes extending to the right of the cell body have emerged from proximal portions of the axon and not the cell body which rests above the plane of the neurites. The bar equals $100 \mu \mathrm{m}$. 
the incorporation of the remaining portion into the cell body, combined with the disruption of the cytoskeletal structures that might be involved in maintaining the unipolar configuration, could trigger multipolar process formation. Clearly, additional studies on the roles of the initial segment and the cytoskeleton in maintaining the morphology of Aplysia neurons are required to resolve this issue.

The ability to manipulate neurite regeneration of identified Aplysia neurons by hemolymph and the presence of the initial axon could allow an examination of several important problems that are difficult to study in vivo. For example, placing identified Aplysia neurons in culture under different conditions may prove useful for answering the following questions. What are the factors that control the initiation and elongation of neuritic processes for different types of cells (motor cells, sensory cells, interneurons, and neurosecretory cells)? How do neurons establish regional specializations and appropriate morphology? In addition, it provides the means for examining the way specific neurons reestablish appropriate chemical connections and how the properties of those connections cana be altered by controlling the pattern of neurite regeneration (Camardo et al., 1983).

\section{References}

Adler, R. M., M. Manthorpe, S. Skaper, and S. Varon (1981) Polyornithine-attached neurite-promoting factors. Culture sources and responsive neurons. Brain Res. 206: 129-144.

Barker, D. L., R. G. Wong, and S. B. Kater (1982) Separate factors produced by the CNS of the snail Helisoma stimulate neurite outgrowth and choline metabolism in cultured neurons. J. Neurosci. Res. 8: 419-432.

Bray, D., and D. Gilbert (1981) Cytoskeletal elements in neu rons. Annu. Rev. Neurosci. 4: 505-524.

Camardo, J., E. Proshansky, and S. Schacher (1983) Identified Aplysia neurons form specific chemical synapses in culture. J. Neurosci. 3: 26142620.

Campenot, R. B. (1977) Local control of neurite development by nerve growth factor. Proc. Natl. Acad. Sci. U. S. A. 74: $4516-4519$.

Collins, F. (1978) Induction of neurite outgrowth by a conditioned medium factor bound to the culture substratum. Proc. Natl. Acad. Sci. U. S. A. 75: 5210-5213.

Collins, F. (1980) Neurite outgrowth induced by the substrate associated material from non-neuronal cells. Dev. Biol. 79: $247-252$.

Dagan, D., and I. B. Levitan (1981) Isolated identified Aplysia neurons in cell culture. J. Neurosci. 1: 736-740.

Fuchs, P. A., J. G. Nicholls, and D. F. Ready (1981) Membrane properties and selective connections of identified leech neurons in culture. J. Physiol. (Lond.) 316: 203-224.

Fuchs, P. A., L. P. Henderson, and J. G. Nicholls (1982) Chemical transmission between individual Retzius and sensory neurons of the leech in culture. J Physiol. (Lond.) 323: $195-210$.

Goodman, C. S., and K. F. Pearson (1982) Neuronal development: Cellular approaches in invertebrates. Neurosci. Res. Program Bull. 20:773-942.

Hadley, R. D., and S. B. Kater (1983) Competence to form electrical connections is restricted to growing neurites in the snail, Helisoma. J. Neurosci. 3: 924-932.

Jessel, T. M., R. E. Siegel, and G. D. Fischbach (1979) Induction of acetylcholine receptors in cultured skeletal muscle by a factor extracted from brain and spinal cord. Proc. Natl. Acad. Sci. U. S. A. 76: $5397-5401$.
Kaczmarek, L., M. Finbow, J. P. Revel, and F. Strumwasser (1979) The morphology and coupling of Aplysia bag cells within the abdominal ganglion and in cell culture. J. Neurobiol. 10: $535-550$.

KandeI, E. R. (1976) Cellular Basis of Behavior, W. H. Freeman \& Co., San Francisco.

Kaneko, C. R. S., M. Meriekel, and S. Kater (1978) Centrally programmed feeding in Helisoma: Identification and characteristics of an electrically coupled premotor neuron network. Brain Res. 146: 1-21.

Koester, J., and E. R. Kandel (1977) Further identification of neurons in the abdominal ganglion of Aplysia using behavioral criteria. Brain Res. 121: 1-20.

Kriegstein, A. R. (1977) Development of the nervous system of Aplysia californica. Proc. Natl. Acad. Sci. U. S. A. 74: 375378.

Kriegstein, A. R., V. Castellucci, and E. R. Kandel (1974) Metamorphosis of Aplysia californica in laboratory culture. Proc. Natl. Acad. Sci. U. S. A. 71: 3654-3658.

Lasek, R. J., and M. L. Shelanski (1981) Cytoskeletons and the architecture of the nervous system. Neurosci. Res. Program Bull. 19: 1-153.

Letourneau, P. C. (1975) Cell-to-substratum adhesion and guidance of axonal elongation. Dev. Biol. 44: 92-101.

Letourneau, P. C. (1978) Chemotactic response of nerve fiber elongation to nerve growth factor. Dev. Biol. 66: 183-196.

Levi-Montalcini, R. (1976) The nerve growth factor: Its role in growth, differentiation and function of the sympathetic adrenergic neuron. Prog. Brain Res. 45: 235-257.

Muller, K. J., J. G. Nicholls, and G. S. Stent (1981) Neurobiology of the Leech, Cold Spring Harbor Laboratory, Cold Spring Harbor, NY.

Murphy, A. D., and S. Kater (1978) Specific reinnervation of a target organ by a pair of identified molluscan neurons. Brain Res. 156: 322-328.

Murphy, A. D., and S. Kater (1980) Sprouting and functional regeneration of an identified neuron in Helisoma. Brain Res. 186: 251-272.

Nicholls, R. G., B. Wallace, and M. Adal (1977) Regeneration of individual neurons in the nervous system of the leech. In Synapses, G. A. Cottrell and P. N. R. Usherwood, eds., pp. 249-263, Academic Press, Inc., New York.

Nishi, R., and D. K. Berg (1981) Two components from eye tissue that differentially stimulate the growth and development of ciliary ganglion neurons in cell culture. J. Neurosci. 1: 505-513.

Patterson, P. H. (1978) Environmental determination of autonomic neurotransmitter function. Annu. Rev. Neurosci. 1: 117.

Ready, D. F., and J. F. Nicholls (1979) Identified neurons isolated from leech CNS make selective connections in culture. Nature 182: 67-69.

Schacher, S., E. R. Kandel, and R. Woolley (1979) Development of neurons in the abdominal ganglion of Aplysia californica. I. Axosomatic synaptic contacts. Dev. Biol. 71: 163-175.

Schacher, S., E. Proshansky, and J. Camardo (1982) Neurite outgrowth and synapse formation of identified Aplysia neurons in dissociated cell culture. Soc. Neurosci. Abstr. 8: 17

Varon, S., and R. D. Bunge (1978) Trophic mechanisms in the peripheral nervous system. Annu. Rev. Neurosci. 1: 327-361.

Winlow, W., and E. R. Kandel (1976) The morphology of identified neurons in the abdominal ganglion of Aplysia californica. Brain Res. 112: 221-249.

Wong, R. G., R. D. Hadley, S. B. Kater, and G. C. Hauser (1981). Neurite outgrowth in molluscan organ and cell cultures. The role of conditioning factor(s). J. Neurosci. 1: 10081021.

Wong, R. G., D. L. Barker, S. Kater, and D. A. Bodnar (1983) Neurite growth promoting activity produced by the central nervous system of Helisoma. Brain Res., in press. 